\section{(Tha Iertures}

$$
\text { ox }
$$

UNICELLULA CANCRI : THE PARASITE OF CANCER.

\author{
Delivered before the Royal College of Surgeons \\ of England.
}

BY

Sir HENRY BUTLIN, BaRT., F.R.C.S., PAST PRESIDENT OF THE ROYAL COLLEGE OF SURGEONS; HONTERIAN
PROFESSOR.

\section{I.-THE PROTOZOA.}

In the Bradshaw Lecture of November, 1905, I put forward the proposition that "the carcinoma cell is an independent organism like many a protozoon ; that it lives a life which is wholly independent and proper to itself and that it lives as a parasite in the body of the animal which is affected with carcinoma, deriving its nourish ment from this host, and doing nothing to repay the host for the sustenance of which it robs him.",

Until shortly before I delivered the lecture I thought that I was the first person to suggest that the cancer cell is itself the parasite of cancer, but $I$ found that Hauser had done so in 1903. ${ }^{2}$ And a couple of years ago Dr. Powell White showed me that he had done so in the Erasmus Wilson Lectures at the Royal College of Surgeons as long ago as $1902 .^{3}$

But I think that neither White nor Hauser had carried the matter to its logical conclusion, so far as to insist that the cancer cell is a new organism-a new creation of animal being-not a mere changed cell.*

So far as I know, then, I stood alone in the belief that the cell of carcinoma is a new creation of living beings, consisting of a single cell, and governed by natural laws just as clear and just as defined as those which govern single-cell organisms which are recognized by naturalists. In 1905 I maintained this view only for the cells of carcinoma. For the last five years and more the matter has been constantly before my mind. A great deal of new information and material has been provided during that period, and I am able now to maintain the view, not only for carcinoma, but for every variety of malignant disease.

I am quite aware that my ignorance of biology and of the lowest forms of animal life may render my attempt ridiculous in the eyes of naturalists. And I should never have ventured to undertake the task had there been any person particularly fitted for it, and willing to accept it. A wide grasp of three kinds of knowledge is required-

A knowledge of the protozoa.

Experience of experimental investigation of cancer. And experience of the clinical pathology of cancer in the human subject.

I do not know any one person. who combines these three kinds of knowledge in himself.

There is only one distinguished protozoologist, so far as I know, who is engaged in the investigation of cancer-
Professor Calkins, of the Columbia University of New York-and he is not a medical man. And it is, I am sorry to say, notorious that the masters of experimental investigation are, for the most part, very ignorant of the clinical pathology of cancer, while it is equally true that the physicians and surgeons who have studied cancer from the clinical and microscopical aspects, are not acquainted with protozoology or with experimental investigation.

The class to which I have the honour to belong-the clinical pathologists-is looked down upon by the other two classes, and I have been told that its day is past. But I claim a right to present my theory on the ground that I have spent a great deal of time in the course of many years in the study of the clinical pathology of cancer, and that I have been closely observant of the actual work of the Imperial Cancer Research since its foundation, have constantly associated with the staff, and have been a member of the Publication Committee of all

* "All the phenomena of malignant and other tumours can be explained on other grounds-viz., on the view that the cells take on an "independent mode of growth, and behave as parasites themselves." they behave a.s independent parasites." (White, loc. cit.) the scientific reports which have been published by the Research. On the other hand, I am wholly dependent for my statements on the life-history of the protozoa on the works of Calkins and Doflein, and the references which I have found in them, and to some pretty sharp criticism of my views in a letter which Professor Calkins was kind enough to write me.

I shall divide the subject into two parts. In the first part I shall endeavour to show that there is no essential difference between cancer cells and certain other parasites in the relation to their host. In the second part I shall show that almost all the phenomena of cancer with which I am acquainted can be readily explained on this theory.

The parasites of which I am going to speak are the protozoa ; I am not going to speak of such micro-organisms as bacilli and bacteria. I use the protozoa not because $I$ intend to insist that the cancer cells must be included amongst the protozoa, but because they most closely resemble the protozoa in their relation to the body of the host, and perhaps in their mutual relations.

Certain of the protozoa appear only to live as parasites, whilst others of them are never parasitic, and others, again, are able to exist either as parasites, or external to the body of any host. The powers of the parasites are strangely and strictly defined. Doflein ${ }^{4}$ (of whose work I am going to make very free use) says :

When a protozoon gets into another organism there begins at once a fight between the two, which ends in an easy victory of the larger, many-celled beast if the protozoon is not a parasite, and if the many-celled beast enjoys its normal natural resistance. But if the protozoon is fitted for parasitism then the ance. But if the protozoon is fitted that parasitism then the fight is in earnest. And in this fight that organism conquers
which is able to overcome the other with its fighting weapons. ${ }^{s}$

But it is quite certain that every parasitic protozoon which finds its suitable host does not succeed in holding its own against the resistance of the host.

Many groups of parasites are limited to certain groups of hosts-the Sarcosporidiidae, for instance, to air-breathing vertebrates-whilst the Gregarinidae have not been found in vertebrate hosts. ${ }^{6}$ But the limitations are much more strict than this. For, of the same species of parasite, different varieties are found in different varieties of a species of host. Thus the Sarcosporidiidae, which are believed to be exclusively found in mammals, ${ }^{7}$ and which have been found in horses, cows, buffaloes, mice, rats, man, etc., do not all occur equally and at random in all these animals, but certain varieties of the Sarcosporidiidae occur only in certain varieties of mammal. Sarcocystis miescheriana inhabits the body of the pig; Sarcocystis tenella loves the sheep; while Sarcocystis muris is a parasite of the house-mouse and the rat. And those varieties of parasite which are particular to certain varieties of mammal, as the Babesia bigemina is to cattle, cannot be implanted in other mammals. Experiments which have been made on rats, guinea-pigs, sheep, and pigeons, have always failed. ${ }^{8}$ On the other hand, there are parasites which can exist in several or many varieties of host, yet even these exhibit strange powers of selection. Thus, Trypanosoma brucei and Trypanosoma lewisi can breed in dogs, in the blood of the same animal, but if they are injected from this blood into rats, Trypanosoma brucei disappears, and only Trypanosoma, lewisi lives and thrives. ${ }^{9}$

Just as particular varieties of protozoa are limited to particular varieties of host, so they are often limited in like manner to particular parts of the bodies of their hosts. Thus, the Sarcosporidiidae are parasites of muscles ; Trypanosoma is a blood parasite ; the Coccidiidae are parasites of cells, particularly of epithelial cells.10 But they exhibit powers of selection much more marked than this. Myxobolus cyprini is a parasite of the kidney epithelium of the carp. The Sarcosporidiidae not only affect the muscles, but most of the varieties affect particular muscles or groups of muscles. Thus, Sarcocystis miescheriana takes to the muscles of the larynx, to the diaphragm, and intercostal muscles; Sarcocystis muris affects the muscles of the trunk. And although several varieties of Sarcosporidiidae are chiefly found in the muscles in the neighbourhood of the alimentary canal, which they may have easily reached from the mouth or oesophagus, others of them are found in muscles far distant from the alimentary canal, such as the intercostal muscles, or the muscles of the trunk.

[2656] 
Other parasites appear to be equally at home in several or many tissues of the host. Nosema bombycis (which produces the pébrine disease of the silkworm) occurs in the intestine, the fat bodies, the sexual organs-in short, in all the organs of the Bombyx mori.

And, far more remarkiable and interesting than this, is the generalization which may take place of parasites which are usually limited to a single structure of the host. Thus, Myxobolus pfeifferi, which is usually a harmless parasite in the kidney of the barbel, makes terrible havoc of the same fish in the water of certain rivers (the Seine, the Marne, the Maas, the Rhine and Mosel), where it attacks almost all the organs of the body of the fish-the connective tissue of the intestine, the kidney, the spleen, the liver, but, above all, the muscular system, in which it forms great lumps and tumours, which stand out on the surface of the animal, and are quite characteristic of the barbel-sickness (Barbenseuche).11 (Figs. 1 and 2.)*

It is possible that the protozoa, which are parasitic (some of them, at least), take an active part in their migration. But they are also carried in the blood and lymph to the organs and tissues in which they are generalized. Thus, Isospora lieberkühni (a parasite of the frog) first attacks the epithelium of the intestine, then penetrates into the vessels of the mucous membrane, and is carried by the blood to the lungs, liver, spleen, and other parts. Entamoeba histolyca, the parasite of dysentery, makes its way through the walls of the rectum, and is supposed to be conveyed through the ductus chole dochus into the liver. Lymphosporidium calkins (which produces severe epidemics in fish) appears in the form of small amoeboid bodies in the lymph, attacks the muscles of the intestines and other organs, passes again into the lymph in its developed form, and produces numerous spores, which are conveyed to all parts of the budy.

It is interesting to observe the changes which take place in many of the protozoa, either to adapt them to parasitism or to altered conditions of life in the bodies of different hosts. Thus, the Trypanosoma will vary in size, in the situation of its nucleus, etc., according to the medium in which it lives. Trypanosoma lewisi loses its undulating membrane in certain artificial cultures, and the Sarcosporidiidae are not constant in form, for the cells, closely packed together during their development, mutually deform one another. ${ }^{12}$

Of liability of animals of the same species to a particular parasite, the evidence goes to prove that some individuals of a species are immune to the attack of a parasite, other individuals recover from the attack of a parasite, while other individuals again suffer badly from it, or die. Take, as an example, the haemoglobinuria of cattle (Texas fever), which is attributed to Babesia bigemina, a parasite which is not directly transferred from cow to cow, but is introduced into the cattle by a beetle (Boophilus annulatus). ${ }^{13}$ Whole herds are attacked in the plains of Texas. But all the animals do not show symptoms of the disease, and some of those which are attacked recover. Pigniéres gives an account of a herd of a thousand adult cattle and 450 calves. Of the adults 630 died-an enormous mortality-but only 10 of the 450 calves perished of the disease. Calves, if they suffer at all, suffer mildly. There is generally no haemoglobinuria, and at the end of a fortnight they are often quite recovered. Nevertheless, the Babesia may still be found in the blood of these recovered calves, so that they appear to have acquired immunity against the poison of the parasite. Whether they can be artificially immunized by the injection of the blood of beasts which have been cured of the disease has not yet been clearly ascertained.

Although some of the parasites are able to take formed nourishment, most of them, and all the cell parasites, live by osmosis. ${ }^{14}$ The Sporozoa, for instance, live exclusively by the osmotic taking of fluid nourishment. ${ }^{15}$ Many of them parish with their host, for even if they escape from the dead body of the host, they may be unable to exist outside the body of a host. But they often exhibit a marked tenacity of life; for they may live for days after the death of the host, and of every tissue and cell of the host.

With regard to the liability of parasitic protozoa to death, it is held by Weismann and his school that the protozoa are immortal, in the sense that the young * The figures illustrating these lectures will be published next week
with the second lecture. animals are in part composed of the substance of the parent. As a matter of fact, they undergo degeneration, are liable to disease, fade, waste, and die, like other living creatures; and they are often killed by the invasion of their bodies by micro-organisms - the bacteria-which are then parasites of parasites. I must ask you to bear this in mind when we come to consider the cells of cancer presently. ${ }^{16}$ It appears probable that the body of the host contains, or may produce on demand, a subtance dangerous to the life of the parasite which is in it. Of this the parasite may die. But if it can withstand the dangerous substance it seems to gain greater strength. It has acquired immunity by its successful resistance to the dangerous substance, and may flourish more actively than before.

But the activity of a parasite is probably not always the same. For, as they show alternate periods of activity and depression in cultures, eating more, growing faster, multiplying abundantly at one time, and displaying sluggard qualities at another (Actinosphaeria, Infusoria, etc.), so it is probable they are subject to similar periods of activity and depression in the body of the host. ${ }^{17}$ Whether, during these periods of depression, they are devoured alive by phagocytes I do not know, but their dead bodies appear to be eaten by phagocytes. ${ }^{18}$

The effect of parasites on their hosts depends largely on whether they produce toxins dangerous to the host or not. Many of them (such as the parasite of malaria) are toxic. And these are naturally much more dangerous to the host than the non-toxic parasites. But their virulence varies, like their vital activity; they are seldom or never so actively virulent as the bacteria and bacilli, and take much longer to produce serious or fatal illness in the host.

The non-toxic parasites are much less dangerous to life. They are often unperceived-are mere "commensales." But they may destroy the cells and tissues which they attack to such an extent as to produce serious effects upon the health of the host. They may destroy the host by enormous increase in numbers, and particularly by interfering with the working of vital organs. I have already mentioned the barbel-sickness, which is so fatal to the fish in France and Germany. The tumours sometimes ulcerate. The Coccidiidae appear to produce their effects by destruction of the tissues they invade. Eimeria stiedae-a common coccidium of the rabbit-causes the formation of tumours which may grow as large as a hazel-nut, and contain fluid, in which are found quantities of epithelial cells and coccidia. ${ }^{19}$ Lymphosporidium calkins (a parasite of fish to which $I$ have already referred) is apt to fill the lymph vessels so full that serious disturbance, the formation of ulcers, and death result from the stoppage of the flow of lymph. ${ }^{20}$ Sarcocystis tenella sometimes chokes sheep by producing great sarcosporidian tumours in the neighbourhood of the air passages. ${ }^{21}$

It seems probabie that some parasites are capable of existing during long periods of time, even when they are not living their usual life, in the sense that a parasite which is, under ordinary circumstances, toxic to the host, may cease to be toxic, yet still exist. Thus, Babesia bigemina is often found in the blood of calves which have long recovered from the disease which it produces. It is well known that human beings who have contracted malaria may recover from it and may live for years without an attack, and then may be suddenly and unexpectedly attacked, even when they have been living meanwhile in non-malarial regions. It is evident the parasite is living in the body of the host during this long period, but it is almost equally evident that it just maintains its existence, and has lost its activity in the face of the increased resistance of the host.

It will be noticed that I have used the' term "power of selection" in speaking of the predilection of particular parasites for particular species of animals, for particular varieties of those species, and for particular organs and tissues of their hosts. The only reasonable explanation of these predilections is that the parasite finds the nourishment suitable to it in the particular host and parts of the host which it infests, or encounters less resistance there. Eimeria stiedae, for instance, which is contained in the grass on which many animals are feeding, must have an opportunity of entering the alimentary canal of cows, of horses, of sheep, and other animals. And undoubtedly it does enter it. But the only one of the animals which feed on the grass in which 
they arc so abundant which harbours and nourishes the parasite is the rabbit. The waters which contain $M y x o-$ bolus pfieifferi also contain Myxobolus cyprini and Myxobolus nerurobius, and all kinds of fish which inliabit these waters must swallow myriads of all three varieties of parasite. But only the one particular parasite thrives in the one particular variety of fish which it affects. I would licep constantly before your minds this explanation of the power of selection of parasitic protozoa.

Before leaving the parasitic protozoa, two characters which they have in common should be referred to. First, whatever office the parasite may serve-whatever effect it may produce on the lost-it, for its own part, has only two objects in vicw, if such an expression is permitted in spcaling of so lowly a creature. It strives to live, and to reproduce - to maintain the individual and to continue the species. If, in a suitable host, it does not succeed in reaching a suitable part of the body within a reasonable period, it will dic, and the species will cease to exist in that host. The rapidity and completeness of its destruction will depend on many circumstances, but the general statement is correct.

Second. it breeds true. The young animals are always of the same species as the animals from which they were derived. I believe some doubt has been expressed whether Haemosporidiidae may not be derived from Flagellidia. I am not competent to speak on this, but it may be stated quite certainly that Sporozoa are not bred from Rhizopoda oi Rhizopoda from Ciliata-that Sarcocystis micscheriand does not become Sarcocystis muris, and that Noscme bombycis never produce Noscma destrucns, or the reverse.:

I now come to the comparison between the cancer cell and the parasitic protozoa in their life-history and their relation to the host. And I proposo to treat it in the reverse order, taking the individual cells first, and dealing with the characters which they have in common afterwards.

First, I must premise that there is no one cell for erery kind of malignant disease, nor is there one cell for the carcinomata and another cell for the sarcomata. Every variety of malignant tumour has its cwn typical coll, and the characters, the selection of locality, and relations of each variety of cancer cell to the host are sharply defined, and differ as widely as, though not more widely than, those of the varieties of protozoa which belong to the same species.

Take first the cells which resemble the cells of the deeper layers of the epiclermis, or of the appendages of the skin. They are very regular in size and shape, and are collected in masses in spaces of the connective tissuc -usually of the skin or subcutancous tissue. The external cells of the group are often modified in shape, and tend to become cubical or even columnar. They seem to have no power of establishing themselves in distant tissues and organs. On the other hand, their. tenacity of life in and around the part in which they first appeared is little less than marvellous.

Next, take the squamous cells. They resemble the cells of the epithelium of the skin, but are not so regular in size and shape, and the nuclei are large--out of proportion to the size of the cell. They form masses, which sometimes recall the natural dipping of the epithelium between the papilla, but often seem to be massed together, with no further design than to find sitting, or eren standing, room. And in this attempt they are often squeezed in such a manner that they may be elongated, and look more like spindle cells than squamous cells. (Fig. 3.) They extend into the spaces between the muscular fibres as they grow beneath the surface, forming columns of cells which are easily clistinguisiable. Whenever they are in close and easy relation with the lymphatic glands, it may be accepted as a rule to which there are few exceptions, that they will find their way into those glands, and will grow and multiply there.

Now, consider the cells of spheroidal type. They collect in spaces of the connective tissue, sometimes in such a manner as to recall the structure of the gland whose epithelium they pattern. They spread along the lymphatic channels, and are conreyed into the lymphatic glands, where they are well received and flourish. They are

* There are other properties on which $I$ mast not to ach, such as the periodicity which some of the protoza exin wo in relation to their 1909, p. 106. 4 conveyed by the blood into other organs. They can live and nultiply in many organs ; but they select, by preference, the liver and lungs, and the medullary tissue of the bones; particularly of the femur and vertebrae of the lumbar region, just as certain Sarcosporidiidae have a liking not merely for muscles, but for certain muscles or groups of muscles. They exhibit a wonderful tenacity of life, for, after lying dormant for many. years (as many as nine or ten or more), they may suddenly thrive and multiply and produce large masses of their like in the space of a few weeks or months. (Fig. 4.) Although they are probably chiefly conveyed to different regions of the body in the form of single young cells, it is also well known that masses of them grow into the interior of blood and lymphatic vessels, ${ }^{23}$ and that the emboli of them may bo carried into parts which are favourable to their reception. It is also known that many of them perish in their journeying. They may be found in blood vessels and in the thoracio duct in a condition of degeneration and decay. (Fig. 5.)

One of the most interesting and favourable objects of study is the columnar or cylindrical cell. It resembles the cells of the columnar glands of the alimentary tract: Its tendency is to arrange itself in the same fashion as the columnar cells are arranged in the glands of the stomach and intestine, sometimes so precisely that it is difficult to believe that the section of the carcinoma is not a section of normal glands. (Fig. 6.) But the imitation is usually much coarser, and there is evidence of slovenly work in the characters and disposition of the cells.

As in the previous case, the cell makes its way into tho surrounding and subjacent tissues, into the lymphatics and lymphatic glands, and is there speedily at home. It also has a great fancy for the liver, and, in a less degree, for the lung, and it now and then grows in the medullary tissue of one of the long bones-the humerus, for example -or such a flat bone as the iliun.

Now consider the group of spinclle cells. They are clongated, tapering at each end. They vary much in size, and their form is often modified by pressure. But the general form is maintained wherever the cells occur. They spread widely in the surropnding tissues. It must be a very wide removal which is to get rid of them. They travel in the blood and in the lymph, so far as we can judge, but although they may thrive in the interior of lymphatic glands, the glands are often free from them. On the other hand, they have a great liking for the lungs, perhaps more than for any other part. They multiply in the lungs so rapidly as to produce large and numerous masses in them, and that is a frequent cause of the death of the liost. These spindle cells are for the most part very strong and vigorous, grow quickly and multiply abundantly, and find subsistence in many organs.

'There is another variety of spindle cell, which multiplies to form tumours. The cells are often of small size, and the outline of the cell may be so faint and the nucleus so distinct that some of them have been called "fibronucleated.". 24 These cells are endowed with very limited powers. They sprearl into the surrounding parts; in these parts they will live and thrive. But they appear quito unable to effect a successful attack upon an'y distant part, for they are not met with in the neighbouring glands, or in the liver, or lungs, or bones, or elsewhere. It is no. excuse to say that their form and size are not favourable to transference by the blood and lymph. They aro small and of convenient shape for transfer, much more so than many large spindle cells which are readily conveyed both by the blood and lymph.

Of the round cells, it may generally be said that it is very difficult to distinguish them from the cells of the masses which make up the infective tumours. (Fig. 7.) Indeed, it is often impossible to do so by their anatomical characters. For the most part, it may be affirmed that they possess a remarkable vitality, not exceeded (seldom equalled) by any other cancer cell. They multiply rapidly, so rapidly, that in some cases they produce immenso masses in a few weeks, and the growth of the mass may be associated with symptoms of general fever. They seem much less influenced by the resistance of the host, or much more capable of finding nourishment, or less dependent on a very special diet, than most other cancer cells. For they seem very little limited to particular organs and tissues compared with most other varieties of cell. They flourish in the lymphatic glands, if they reach them, in tône bones, 
skin and subcutaneous tissue, kidneys, liver, lungs-indeed; like Nosema bombycis, almost everywhere. I believe they would spread all over the body, if the host were not destroyed by them before they have had the opportunity to do so.

There is one variety of cell which I must not pass over without notice-the Giant Cell. These cells only form a certain proportion of the masses in which they occur-less than one-half-and the remainder of the mass is composed usually of spindle cells. Having regard to their size alone, it is not. surprising that giant cells travel with difficulty in the blood and lymph.

It would be expected that the spindle cells of which the mass is chiefly formed might travel and establish themselves in other places. But it is notorious that they seldom do so.

These examples will suffice to illustrate the life-history of some of the resemblances of the cancer cells to the parasitic protozoa. It will be seen that they are as careful in the selection of locolity as are the varieties of parasitic protozoa. They spread in the interstices of the tissues in which they first appear, as do certain of the protozoa. They are conveyed in the blood and lymph, as the parasitic protozoa are. They are deposited in distant tissues and organs, like the parasitic protozoa, and they show just the same predilection for certain tissues and organs as do the protozoa. They are like many of the parasitic protozoa in the fact that they live almost entirely by osmosis. Like the protozoa, they sometimes live for long periods of time in the body of the host without any sign of their presence, and perhaps in a state of lethargy, until their vigour and activity are restored to them by some lowering of the resistance of the host, or by some change in the part in which they have been lying, which renders it more suitable to their necessities. They do not appear to furnish toxins which are dangerous to the health of the host, so that their effects are produced (like the effects of such parasites as Myxobolus pfeifferi) by mechanical causes-destruction of the tissues in which they live and multiply, the stoppage of blood and lymphatic vessels, and the changes consequent on this stoppage. These conditions are naturally more dangerous when they affect the vital parts. On the other hand, when, like the protozoa, the cancer cells are attacked by pathogenic organisms, bacteria and bacilli (as is almost invariably the case when they become exposed), they are rapidly destroyed, sometimes in great masses, and the effect upon the host is đisastrous.

Some cancer cells can live for a long time outside the body of the host, although they do not, so far as we know, belong to the class of organisms which are sometimes parasitic, sometimes not parasitic. I am not aware of any investigations to discover the longest period during which cancer cells can exist outside the body of the host. We want further information on this point. But it is certain that they can live for weeks in glass tubes and then be implanted, as if they were but just taken from the mass in which they lived. At present the cancer cells can only be implanted with success in animals of the same species as the animal from which they were taken. In this respect, again, they resemble certain of the protozoa. It may be that, with greater practice and experience, they will be induced to grow and multiply in animals of a different species, but I very much doubt it, just as I doubt whether Babesia bigemina-a parasite of cattle-will be successfully implanted in a sheep.

Cancer cells, like the parasitic protozoa, are never transformed into tissues of the host, and the structures which they cause to be built up are for their own service, not for the service of the host. They are not themselves transformed into any other kind of tissue, nor do they transform the cells of the body into cancer cells. From the moment they are first unmistakably cancer cells, they remain eancer cells, and, from that moment, they pursue only those two objects which are pursued by the protozoa - to live and to reproduce. And if they fail in these objects, both the individual and the species perish. Of this ample evidence has been furnished in these last years, particularly by the Imperial Cancer Research for animals, and by Sir Alfred Pearce Gould tor man. ${ }^{25}$ In reproduction they breed as true as any protozoon. Not only do carcinoma cells reproduce carcinoma cells, and not sarcoma cells, but it is invariably the same variety of cell which is reproduced, with the same properties and powers and characteristics

It has been said that the cancer cells differ from the protozoa in the circumstance that they are not constant in their method of reproduction, that they multiply by budding or by mitosis, as pleasés them, and that the protozoa never do so.

If all the protozoa were thrown into a common receptacle for study, they would also be found to vary in their methed of reproduction. I believe it is only because the cancer cells have been treated in this fashion that they stem to be subject to no method. But, separate them, and sturly them in families, and I think it will be found that they are just as bound in this respect as the families of protozua. I suspect that the old rule which was laid down-I do not remember by whom or exactly when-is as correct now as it was - that the cells of carcinoma multiply by endogenous multiplication, and that the cells of sarcoma multiply by fission or by budding. The terms used may be clifferent, but I suspect the facts will be the same.

I will not describe the physiological characters of the cancer cell in my own terms, for fear it should be thought that I exaggerate. I will quote Professor Calkins : ${ }^{26}$

Functionally the carcinoma cell is a more perfect type than its orderly colleagues of the epithelium. It talies in and assimilates abundance of food. grows rapidly (especially when near the immediate source of food-that is, at the growing edge), and reproduces its kind through the same complicatci processes that characterize free living cells. In short, it is a processes that characterize free living cells. In short, it is a complete animal organism in itself, simulating in many ways the parasitic protozoon, but differing in some of the most
important respects connected with the continued life of the latter.

I understand that the important respects in which the cancer cell differs from the parasitic protozoa are:

1. "That the cancer cell, so far as we know, undergoes no processes analogous to fertilization." 27

2. "That it cannot live apart from the organism in which it grows; it cannot be cultivated on artificial media, as we cultivate amoebae and flagellates." 28

To the second of these objections it is already claimed by two workers in the Rockefeller Institute that they have cultivated cancer cells in artificial media.

To the first, one can only say that if, in the future, no process analogous to fertilization is discovered in the lifehistory of the cancer cells, it is evident that the import of the process of fertilization will have to be reconsidered.

If the cancer cell does not conform, in all respects, to the laws which are believed to govern the protozoa, it will still remain "a complete animal organism in itself." A new phylum will have to be founded for it, and laws drawn up appropriate to its life.

REFERENCES.

1 British Medical Jodrnal, 1905, ii, 1566. 2 Ziegler's Beitrïgr " Path. Anat.. Xxxiil, S. 1, 1903. Lancet, 1902, i. " References " in are to Dollein's ${ }^{2}$

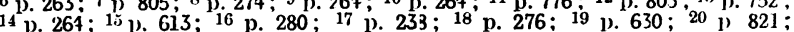
21 p. 811 ; 22 p. 739. 23 Goldmann studien zur. Biologie der bösartigru Neubildungen, Tübingen, 1911. 21 Paget, Lectures on Surfical P!! thr. logy, 1853, vol. ii, p. 155. 25 Gould, Bradshaw Iecture, 1910 . 26. $7 \cdot \cdots \cdots \cdots$. of Exper. Med., x, p. 286, 1908, 27 Calkins, unpublis'sed letter. ${ }^{23}$ Idem.

THE million dollar fund for McGill University, Montreal, reached, the Times correspondent states, 333,000 dollar's $(£ 66,000)$ on the first day. This included 100,000 dollar's telegraphed from London by Dr. James Douglas, VicePresident of the American Institute of Mining Engincers, and formerly Professor of Chemistry in Morrin College, Quebec.

THE second International Congress of Entomology will be held at Oxford from August 5th to 10th, 1912, under the presidency of Professor E. B. Poulton, D.Sc., F.R.S. The Executive Committee proposes to find for members of the Congress lodgings in the town, or rooms in one or more of the colleges at a moderate charge, and invites an early provisional notice of intention to join the Congress, in order that the necessary arrangements may be made. The Proceedings of the first Congress held last year in Brussels are in the press, and will be published shortly. All communications and inquiries should be addressed to the General Secretary of the Executive Committee, Dr. Malcolm Burr, c.o. the Entomological Society of London. 11, Chandos Street, Cavendish Square, London, W. 